\title{
A Scary Complication: Single-center Study on Management and Outcome of Cesarean Scar Pregnancy
}

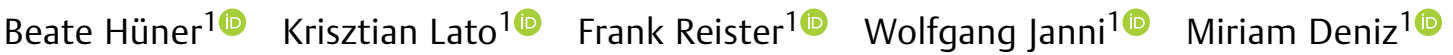 \\ ${ }^{1}$ Department of Obstetrics and Gynecology, Ulm University, \\ Ulm, Germany \\ Address for correspondence Beate Hüner, Department of Obstetrics \\ and Gynecology, Ulm University, Prittwitzstr. 43, 89075 Ulm, \\ Germany (e-mail: beate.huener@uniklinik-ulm.de). \\ Rev Bras Ginecol Obstet 2021;43(4):311-316.
}

\begin{abstract}
Keywords

- scar pregnancy

- therapy scar pregnancy

- ectopic pregnancies

- cesarean section

- hysterectomy

A cesarean scar pregnancy (CSP) is a scary and life-threatening complication of cesarean section (CS). Nevertheless, the incidence of CS is constantly growing. The CSP incidence is $0,15 \%$ of pregnancies after CS which represents $6,1 \%$ of all ectopic pregnancies in women with condition after CS. Therefore, it should be more present in the clinical daily routine. From mild nonspecific symptoms to hypovolemic shock, diagnosis and therapy must be performed quickly. With the progressive growth of the scar pregnancy, a uterine rupture involves the risk of severe bleeding, and an emergency hysterectomy could be necessary. Prolongation of pregnancy has been successful only in a few cases. We report 11 cases from our hospital in the past 10 years. In the discussion, treatment options of this complication with an increasing incidence, which is associated with serious morbidity and mortality, are presented based on the current literature. Treatment options include drug therapy, but also surgical or combined procedures with radiological intervention.
\end{abstract}

\section{Introduction}

A scary and life-threatening complication of cesarean section (CS) is a cesarean scar pregnancy (CSP). Nevertheless the incidence of CS is continuously growing, ${ }^{1}$ with $30,5 \%$ in Germany $^{2}$ and even $55,8 \%$ in Brazil. ${ }^{3}$ This increases the risk of short- and long-term complications, such as postpartum bleeding, uterine rupture, abnormal placental invasion (placenta accreta, increta, percreta), infertility, and ectopic pregnancies. ${ }^{4} \mathrm{~A}$ total of $2 \%$ of all pregnancies are ectopic, with an upward trend; since the 1970s, the incidence has increased from $0,5 \%$ to $2 \% .^{5} \mathrm{~A}$ very rare complication as a result of a previous CS is the implantation of an ectopic pregnancy in the area of the scar, an ectopic scar pregnancy. ${ }^{4}$ This is a new form of ectopic pregnancies, first described in $1978 .{ }^{6}$ The CSP incidence is $0,15 \%$ of pregnancies after CS. This represents
$6,1 \%$ of all ectopic pregnancies in women with condition after $\mathrm{CS}^{7}{ }^{7}$ The period for the appearance of scar pregnancy after CS can range from 6 months to 12 years. ${ }^{8}$ It is unclear whether the suture technique for closing the uterotomy has an influence on the formation of scar pregnancy. ${ }^{9}$ The role of the frequency of previous sections is controversially discussed. ${ }^{7,10}$ Other risk factors include repeated uterine curettage, Asherman syndrome, myomectomy, and in vitro fertilization (IVF) therapies. ${ }^{11}$

Furthermore, the condition after a cesarean scar pregnancy may increase the risk of recurrence of cesarean scar pregnancy, miscarriage, preterm birth or an abnormal invasion of the placenta. ${ }^{12}$ Recently, studies hypothesize that a cesarean scar pregnancy could be a precursor of an abnormally invasive placenta. Although this pathology is often detected primarily in the $2^{\text {nd }}$ or $3^{\text {rd }}$ trimester, the early received

August 22, 2020

accepted

January 6, 2021
DOI https://doi.org/

10.1055/s-0041-1728781. ISSN 0100-7203. (c) 2021. Federação Brasileira de Ginecologia e Obstetrícia. All rights reserved.

This is an open access article published by Thieme under the terms of the Creative Commons Attribution License, permitting unrestricted use, distribution, and reproduction so long as the original work is properly cited. (https://creativecommons.org/licenses/by/4.0/)

Thieme Revinter Publicações Ltda., Rua do Matoso 170, Rio de Janeiro, RJ, CEP 20270-135, Brazil 
invasion of the uterine scar by trophoblastic tissue could be detectable during the first trimester scan. ${ }^{13}$

Two forms of scar pregnancies are distinguished. The first form is an ectopic pregnancy in the cesarean scar, which grows to the cervicoisthmic space and toward the uterine cavum (endogenous type or Type I). The second form grows toward the bladder and the abdominal cavity and carries a higher risk of rupture (exogenous type or Type II). ${ }^{14,15}$

In the exogenous form of scar pregnancy (Type II), the placental tissue abnormally invades the myometrium as an early form of an adherent placenta. If the pregnancy persists, serious complications are likely to occur. Few cases with successful prolongation of pregnancy have been published. ${ }^{16,17}$ However, a hysterectomy had to be performed due to a pathologic placenta invasion. ${ }^{17}$

Between the $5^{\text {th }}$ and $16^{\text {th }}$ week of pregnancy, the scar pregnancy becomes noticeable. Symptoms can be variable. A total of $39 \%$ of the patients show mild, nonpainful vaginal bleeding, and $16 \%$ of the patients indicate moderate to severe abdominal pain. However, up to $37 \%$ of the cases can also be found randomly in asymptomatic patients. ${ }^{7}$ The most feared complication is uterine rupture with hemorrhagic shock up to the death of the patient. ${ }^{8}$

Scar pregnancy is diagnosed first with the help of transvaginal ultrasound, showing an empty uterus cavum and an empty cervical canal with no contact to the gestational sac. This is located in the anterior part of the lower uterine segment with or without a defect of the myometrium between the gestational sac and the bladder. ${ }^{9}$ A threedimensional (3D) ultrasound or magnetic resonance imaging (MRI) can be used for further diagnosis.

The description of the relationship between the gestational sac of the cesarean scar pregnancy, the previous cesarean scar and the thickness of the anterior uterine wall is very important for the prediction of the outcome and for the planning of further therapies. ${ }^{18}$ A cesarean scar pregnancy on top of a well-healed scar had a better outcome than in cases in which the pregnancy was located in the niche of a dehiscent scar. ${ }^{19}$

So far, there is no guideline or gold standard for the treatment of scar pregnancies. The discussion compares the various therapies.

\section{Cases at the UIm University Hospital between 2009 and 2019}

In the past 10 years, we have treated 11 cases of scar pregnancy due to a previous CS ( - Table 1). A total of seven patients had only one CS before, one patient was in condition after two CS, and two patients had condition after three sections. The diagnosis was always made with transvaginal ultrasound in the $1^{\text {st }}$ trimester when the pregnancy seat was unclear ( $\mathbf{- F i g . 1}$ ). In seven cases, a positive heart action was shown. The beta human chorionic gonadotropin ( $\beta-\mathrm{HCG}$ ) value ranged from 8.000 to $128.000 \mathrm{IU} / \mathrm{l}$. Symptoms ranged from under-period vaginal bleeding to severe lower abdominal pain with over-period bleeding (-Table 2 ).
Table 1 Cases

\begin{tabular}{llllll}
\hline ID & $\begin{array}{l}\text { Age } \\
\text { (years old) }\end{array}$ & Gravida & Para & $\begin{array}{l}\text { Number of } \\
\text { Cesarean } \\
\text { Sections }\end{array}$ & $\begin{array}{l}\beta \text {-HCG } \\
\text { value }\end{array}$ \\
\hline Case 1 & 38 & 4 & 3 & 2 & 16.369 \\
Case 2 & 37 & 3 & 2 & 1 & 8.341 \\
Case 3 & 39 & 4 & 4 & 1 & 45.651 \\
Case 4 & 42 & 3 & 3 & 1 & 73.040 \\
Case 5 & 30 & 4 & 3 & 3 & 90.231 \\
Case 6 & 37 & 8 & 3 & 2 & 6.303 \\
Case 7 & 24 & 2 & 1 & 1 & 57.833 \\
Case 8 & 29 & 2 & 1 & 1 & 75.000 \\
Case 9 & 40 & 2 & 1 & 1 & 20.365 \\
Case 10 & 37 & 3 & 1 & 1 & 128.758 \\
Case 11 & 28 & 4 & 3 & 3 & 85.142 \\
\hline
\end{tabular}

In all cases, an individualized therapy planning was discussed; most of the time, initially, with methotrexate (MTX). So far, there is no defined treatment algorithm or participation in a randomized trial in our center.

In 10 cases, a detailed consultation with the patients regarding the various treatment options was held, considering the risks and the option of preserving future fertility. In one case (Case 6), a hysterectomy had to be performed after a short consultation due to severe vaginal bleeding. The treatment was performed both on an outpatient and inpatient basis with close-meshed laboratory controls. In one case (Case 3), the scar pregnancy was discovered by chance during laparoscopic surgery, which initially suspected of an ectopic pregnancy in the fallopian tube and could be removed preserving the uterus. No patient wanted a prolongation of the pregnancy.

A total of nine patients were initially treated with methotrexate (MTX). Three patients received the application intramuscularly (IM) (Cases 1, 2, and 8), and in 1 case

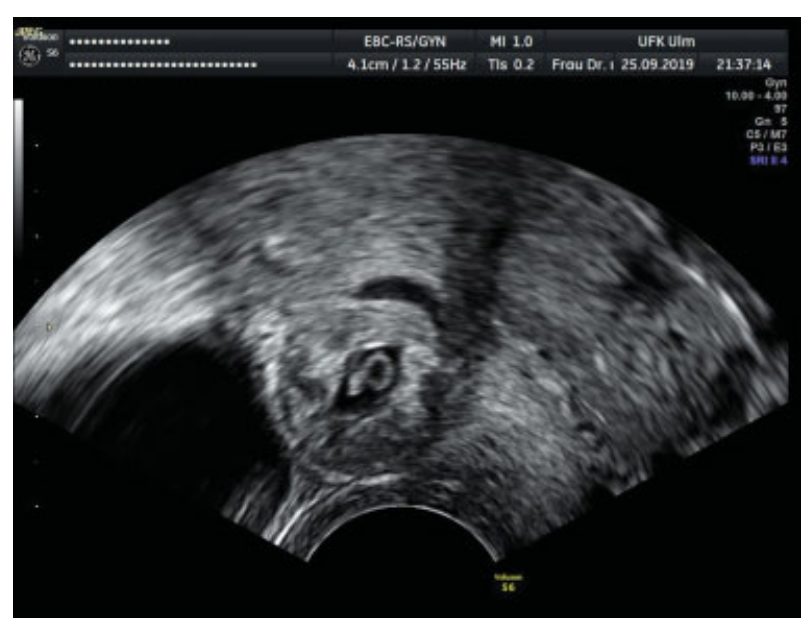

Fig. 1 Ultrasound picture of a scar pregnancy. 
Table 2 Complications, therapy, and outcome

\begin{tabular}{|c|c|c|c|c|c|c|}
\hline ID & Bleeding & First-line therapy & $\begin{array}{l}\text { Week of } \\
\text { pregnancy }\end{array}$ & $\begin{array}{l}\text { Positive } \\
\text { heartbeat }\end{array}$ & Hysterectomy & Additional therapy \\
\hline Case 1 & Yes & MTX 1x IM & 9 & No & No & $\begin{array}{l}\text { Foley catheter, } \\
\text { curettage }\end{array}$ \\
\hline Case 2 & Yes & MTX 1x IM & 7 & No & Yes & No \\
\hline Case 3 & No & No & 6 & Yes & No & $\begin{array}{l}\text { Laparoscopy (ectopic pregnancy } \\
\text { expected in the fallopian tube) }\end{array}$ \\
\hline Case 4 & Yes & MTX i IM and intralesional & 8 & Yes & Yes & No \\
\hline Case 5 & No & MTX IM and intralesional & 10 & Yes & Yes & Mifegyne, cytotec \\
\hline Case 6 & Yes & Hysterectomy & 8 & Yes & Yes & No \\
\hline Case 7 & No & MTX IV & 9 & No & No & No \\
\hline Case 8 & Yes & MTX IM & 9 & Yes & No & $\begin{array}{l}\text { Excision with reconstruction } \\
\text { of the uterus }\end{array}$ \\
\hline Case 9 & No & MTX IM and intralesional & 7 & No & No & Curettage \\
\hline Case 10 & Yes & MTX IM and intralesional & 9 & Yes & Yes & No \\
\hline Case 11 & No & MTX IM and intralesional & 7 & Yes & Yes & No \\
\hline
\end{tabular}

Abbreviations: IM, intramuscular; IV, intravenous; MTX, methotrexate.

(Case 7) an intravenous (IV) therapy was performed. In 5 cases (Cases 4, 5, 9, 10, and 11), MTX therapy was administered IM and intralesional controlled by ultrasound. For five patients who received MTX therapy, a hysterectomy was then performed due to an increasing vaginal bleeding and pain. Of these, four patients had received MTX IM. and intralesional. In three cases, uterus preservation was successful. In two cases, an additional curettage followed, once with the insert of a foley catheter for bleeding control after the curettage. In one case (Case 8) the excision of scar pregnancy with preservation of the uterus was achieved after MTX application.

For one patient (Case 6), due to severe bleeding and pain, no MTX therapy could be performed, and with completed family planning, laparoscopic hysterectomy was performed directly (-Fig. 2 ).

Unfortunately, there is no follow-up to the reproductive outcome after the treatment.

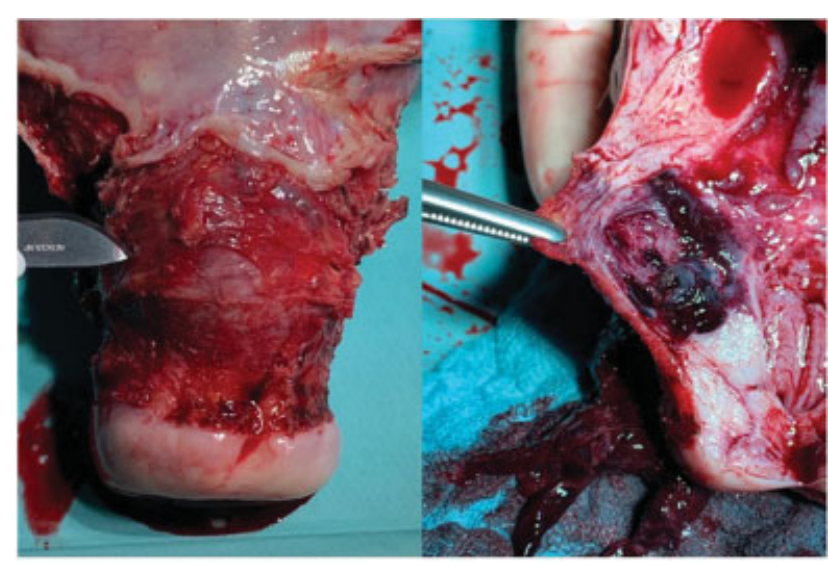

Fig. 2 Scar pregnancy removed by laparoscopic hysterectomy.

\section{Discussion}

Cesarean scar pregnancy is a very rare form of ectopic pregnancies. As a result, there is no treatment algorithm or gold standard for a therapy. The literature provides mainly case reports or studies with small case series without clear evidence regarding a preferred treatment method. Since 2001, however, the number of published cases has increased in the context of the worldwide rise of CSs. Therapy selection depends on symptoms and associated urgency of the treatment, as well as on the desire for prolongation of the pregnancy, preservation of the uterus, and further family planning. The various options should be discussed in advance with the patient, considering the risks and opportunities of the respective method.

\section{Expectant Treatment}

If desired, an expectant treatment with appropriate clarification can be considered. In particular, the increased risk of uterine rupture and placental implantation disorder with massive blood loss and emergency hysterectomy must be pointed out. In a series of 64 cases, a wait-and-see procedure was performed with 5 patients. In 1 case, there was a live birth in the $36^{\text {th }}$ week, discharged by elective CS followed by a hysterectomy due to a placental implantation disorder. $^{20}$

A systematic review of 17 studies also examines the waitand-see strategy. Here, with positive heart action, a high risk of bleeding and, consequently, of surgical intervention in the $1^{\text {st }}$ trimester is concluded. A total of $13 \%$ of the patients had an uncomplicated abortion, $20 \%$ needed surgical intervention, 9.9\% suffered a uterine rupture, and 15,2\% had a hysterectomy in the $1^{\text {st }}$ or $2^{\text {nd }}$ trimester. If the pregnancy could be prolonged until the $3^{\text {rd }}$ trimester, 3 out of 4 patients presented with placenta percreta. ${ }^{4}$ 
A study of 60 scar pregnancies describes a wait-and-see procedure with intact pregnancies in 10 cases. $^{17}$ In 4 cases, there was a live birth by elective CS between the $32^{\text {nd }}$ and $36^{\text {th }}$ week. In three cases, a hysterectomy had to be performed on placenta percreta. In our collective, no patient wanted a wait-and-see approach.

If a treatment becomes necessary, it should be applied in the $1^{\text {st }}$ trimester, as a pregnancy increases the risk of a rupture with massive bleeding and hypovolemic shock. The treatment must be tailored to the maintenance of fertility, gestational age, clinical symptoms, and defects in the area of the myometrium. ${ }^{9}$ Treatment options include pharmacological, radiological, surgical, and combined procedures, with up to 30 different options.

\section{Foley Catheter}

A simple method is a curettage with a previous insertion of a foley catheter. In a study on this procedure, 311 patients with an asymptomatic endogenous scar pregnancy up to the $8^{\text {th }}$ week were included. A foley catheter was used for compression over 24 hours and the patients underwent a curettage afterwards. Subsequently, $\beta$-HCG follow-up checks confirmed the success. The success rate was of $90,7 \%$, with a shorter duration of treatment than with MTX therapy alone. ${ }^{21}$ A similar outcome is observed in another study using a double balloon catheter. ${ }^{22}$ This method was successfully applied in one of our cases (Case 1) with additional application of MTX IM.

\section{Methotrexate}

The application of MTX is established in the therapy of ectopic pregnancy. This conservative therapy method can also be used in the treatment of ectopic scar pregnancy. Beta human chorionic gonadotropin values $<5.000 \mathrm{IU} / \mathrm{I}$ with a dosage of $50 \mathrm{mg} / \mathrm{m}^{2}$ show a good response. ${ }^{23}$ This treatment is a good option, especially for asymptomatic and hemodynamically stable patients before the $8^{\text {th }}$ week without signs of rupture and a myometrium thickness of $<2 \mathrm{~mm}$ between the scar pregnancy and the bladder. ${ }^{9}$

The application can be performed ether IV or IM if necessary, in combination with an intralesional injection. In our collective, MTX therapy was performed in a total of nine patients. In three cases, the therapy was performed IM; in 5 cases, MTX intralesional was applied additionally; and in only 1 case IV therapy was performed. A hysterectomy was ultimately necessary in 5 of the MTX pretreated cases. In four of these cases, a positive heart action was seen in the ultrasound.

\section{Combined Procedures}

In addition to single MTX therapy, the literature also contains a variety of combined methods. For example, in a study with 107 patients, the treatment with curettage alone or with a previous application of MTX IM or IV regardless of the of the $\beta$-HCG value. The complication rate did not differ in this study, only longer hospitalization due to MTX treatment was observed. $^{24}$
In a larger case that observed 60 patients, the application of MTX intralesional is described for 33 patients in case of positive heartbeat. In addition, the patients received MTX systemically. For bleeding prophylaxis, a foley catheter was inserted after intralesional application. In 31 cases, there was an abortion. With negative cardiac action, no intervention was performed, and 10 patients had a spontaneous abortion. ${ }^{17}$ In our sample, we performed an intralesional MTX application in 4 cases with positive heart action. In all cases, a hysterectomy became necessary (see - Table 1, Cases 4, 5, 10, and 11).

The disadvantage of single drug therapy may be the increased risk of bleeding and rupture, as a possibly preexisting dehiscence of the scar due to the CS or the beginning of rupture of the uterus might not be recognized. ${ }^{25}$ If this procedure is planned, it is necessary to know about further family planning.

In a retrospective case control study, the application of MTX in combination with other therapy methods is investigated. A total of 103 patients diagnosed with ectopic scar pregnancy received either MTX in combination with surgical therapy (curettage, laparoscopy, hysteroscopy), MTX in combination with embolization of the uterine artery, or sole surgical intervention. For the application of MTX, a distinction was made between systemic and local administration. Therapeutic effect and outcome were compared. The greatest risk of bleeding and residual surgeries was the sole surgical intervention group. The best treatment option in terms of safety and effectiveness was the combination of local ultrasound-controlled MTX injection and surgical procedures. ${ }^{26}$

In another study, 33 patients were treated with either MTX or embolization of the uterine artery or with intraarterial MTX infusion by catheter directly into the uterine artery with subsequent uterine embolization and curettage. Triple therapy is shown here as a more feasible and advantageous variant. ${ }^{11}$ This has not yet been performed in our collective. But in the future, with in interdisciplinary cooperation with radiologists, this could be an option for uterus-preserving therapy.

\section{Operational Procedures}

In addition to pharmacological therapy, there is a variety of surgical options for the therapy of scar pregnancies. This includes, among others, laparoscopy with organ-preserving resection, performed for the first time by Lee et al. in 1999.27 This method is possible with a stable patient and according to surgical experience. In the case of complications from bleeding and hemodynamic instability, a laparotomy must be performed. ${ }^{9}$ In our sample, and organ-preserving resection of the scar pregnancy was performed twice (see - Table $\mathbf{1}$, Cases 3 and 8).

In the literature, there are mainly surgically combined methods. For example, a study examined laparoscopy with hysteroscopy versus curettage with additional embolization of the uterine artery as a basic measure. The sample comprised 58 patients between 2005 and 2010. The group with combination of laparoscopy and hysteroscopy showed a significantly higher resection rate (100 versus $79 \%$ ), with a 
lower blood loss ( $78 \mathrm{ml}$ versus $258 \mathrm{ml}$ ), and a satisfactory reconstruction of the cesarean scar pregnancy was possible (96 versus 25\%). ${ }^{28}$ This can be beneficial in case of further family planning, in order to reduce the risk of rupture in subsequent pregnancies.

In total, $>30$ treatment options can be found in the literature. A systematic review highlights five of them. ${ }^{1}$ One variant is the removal by transvaginal access based on another case series with 23 patients. This seems to be a promising option for exogenous ectopic pregnancies. ${ }^{29} \mathrm{Em}$ bolization of the uterine artery in combination with curettage and hysteroscopy, as described above as an operationally easy method to perform, can be a low-risk intervention. However, implementation is often limited by the existing infrastructure. A new option seems to be the repeated ultrasound-assisted highly focused ultrasound, but this has not yet been established. Laparoscopy, as a superior method of laparotomy, is particularly suitable for the growth of the pregnancy toward the serosa and for defect restoration of the uterine scar. ${ }^{1}$

In summary, an established gold standard is lacking, as well as large multicenter studies. The choice of therapy is therefore mainly dependent on the operational expertise and the availability of the method in the respective clinic.

\section{Conclusion}

Cesarean scar pregnancy is a rare but increasing iatrogenic complication. It should be diagnosed early in the $1^{\text {st }}$ trimester. For this purpose, transvaginal ultrasound is suitable. In addition, 3D ultrasound or MRI can be applied. It seems useful to differentiate between endogenous or exogenous scar pregnancy and to consider the thickness of the myometrium to better assess the respective options. Unfortunately, this cannot be reproduced in our collective. In addition, the planning of the treatment depends on existing heart action. Negative cardiac action is more likely to occur in a noncomplicated abortion event. A wait-and-see behavior with positive heart action can only be discussed in individual cases due to serious complications with increasing growth. In the cases described so far, a hysterectomy had to be performed in almost all cases due to an abnormally invasive placenta or to a uterine rupture. The history and risks of the patient should be considered in the preoperative discussion, depending on the family planning and treatment request of the patient. Ideally, the therapy takes place in the $1^{\text {st }}$ trimester. Various conservative medications as well as surgical or combined methods, including embolization of the uterine artery, exist. There is no established standard of treatment. The choice of therapy depends on the symptoms, on the location of the ectopic pregnancy (Type I or Type II), on the $\beta$-HCG value, and on the desire for fertility preservation. In summary, it can be concluded from our cases that more than half of the women (6 out of 11) had to undergo a secondary hysterectomy, despite drug pretreatment with MTX. Additional intralesional application did not reduce the risk for that. In the presence of a positive heartbeat, a hysterectomy had to be performed in five cases. Combined methods with emboliza- tion of the uterine artery have not been used so far, but could represent a new perspective with existing infrastructure. Unfortunately, we do not have a well-established treatment algorithm so far, and an interdisciplinary cooperation is developable. Further large prospective studies with an objective protocol of perinatal diagnostic, management and long term-follow up including the reproductive outcome would be helpful to establish the optimal treatment of cesarean scar pregnancies. Due to the risk of recurrence of scar pregnancy and abnormal invasion of the placenta, an early ultrasound should be performed in specialized centers in further pregnancies. In the future, the risk of this complication after CS will likely increase and should be kept in mind. Early diagnosis, including for asymptomatic patients, as well as transfer to centers with interdisciplinary expertise in the treatment of scar pregnancies is important for the outcome.

\section{Conflict of Interests}

The authors have no conflict of interests to declare.

\section{References}

1 Birch Petersen K, Hoffmann E, Rifbjerg Larsen C, Svarre Nielsen H. Cesarean scar pregnancy: a systematic review of treatment studies. Fertil Steril. 2016;105(04):958-967. Doi: 10.1016/j. fertnstert.2015.12.130

2 30,5\% der Krankenhausentbindungen per Kaiserschnitt im Jahr 2017 [Internet]. Statistisches Bundesamt. 2018 [cited 2020 Sep 18]. Available from: https://www.destatis.de/DE/Presse/Pressemitteilungen/2018/09/PD18_349_231.html

3 Rudey EL, Leal MDC, Rego G. Cesarean section rates in Brazil: Trend analysis using the Robson classification system. Medicine (Baltimore). 2020;99(17):e19880. Doi: 10.1097/MD.0000000000019880

4 Calì G, Timor-Tritsch IE, Palacios-Jaraquemada J, Monteagudo A, Buca D, Forlani F, et al. Outcome of Cesarean scar pregnancy managed expectantly: systematic review and meta-analysis. Ultrasound Obstet Gynecol. 2018;51(02):169-175. Doi: 10.1002/ uog. 17568

5 Doroszewska K, Milewicz T, Bereza T, Horbaczewska A, Komenda J, Kłosowicz E, et al. Cesarean scar pregnancy - various methods of treatment. Folia Med Cracov. 2019;59(02):5-14

6 Larsen JV, Solomon MH. Pregnancy in a uterine scar sacculus-an unusual cause of postabortal haemorrhage. A case report. S Afr Med J. 1978;53(04):142-143

7 Rotas MA, Haberman S, Levgur M. Cesarean scar ectopic pregnancies: etiology, diagnosis, and management. Obstet Gynecol. 2006; 107(06):1373-1381. Doi: 10.1097/01.AOG.0000218690.24494.ce

8 Seow KM, Huang LW, Lin YH, Lin MYS, Tsai YL, Hwang JL. Cesarean scar pregnancy: issues in management. Ultrasound Obstet Gynecol. 2004;23(03):247-253. Doi: 10.1002/uog.974

9 Ash A, Smith A, Maxwell D. Caesarean scar pregnancy. BJOG. 2007;114(03):253-263. Doi: 10.1111/j.1471-0528.2006.01237.x

10 Jurkovic D, Hillaby K, Woelfer B, Lawrence A, Salim R, Elson CJ. Firsttrimester diagnosis and management of pregnancies implanted into the lower uterine segment Cesarean section scar. Ultrasound Obstet Gynecol. 2003;21(03):220-227. Doi: 10.1002/uog.56

11 Ding W, Zhang X, Qu P. An efficient conservative treatment option for cervical pregnancy: transcatheter intra-arterial methotrexate infusion combined with uterine artery embolization followed by curettage. Med Sci Monit. 2019;25:1558-1565. Doi: 10.12659/ MSM.913262

12 Morlando M, Buca D, Timor-Tritsch I, et al. Reproductive outcome after cesarean scar pregnancy: A systematic review and 
meta-analysis. Acta Obstet Gynecol Scand. 2020;99(10):1278-1289. Doi: 10.1111/aogs.13918

13 D'Antonio F, Timor-Tritsch IE, Palacios-Jaraquemada J, Monteagudo A, Buca D, Forlani $F$, et al. First-trimester detection of abnormally invasive placenta in high-risk women: systematic review and meta-analysis. Ultrasound Obstet Gynecol. 2018;51 (02):176-183. Doi: 10.1002/uog.18840

14 Gonzalez N, Tulandi T. Cesarean scar pregnancy: a systematic review. J Minim Invasive Gynecol. 2017;24(05):731-738. Doi: 10.1016/j.jmig.2017.02.020

15 Vial Y, Petignat P, Hohlfeld P. Pregnancy in a cesarean scar. Ultrasound Obstet Gynecol. 2000;16(06):592-593. Doi: 10.1046/j.14690705.2000.00300-2.x

16 Herman A, Weinraub Z, Avrech O, Maymon R, Ron-El R, Bukovsky Y. Follow up and outcome of isthmic pregnancy located in a previous caesarean section scar. Br J Obstet Gynaecol. 1995;102 (10):839-841. Doi: 10.1111/j.1471-0528.1995.tb10855

17 Timor-Tritsch IE, Khatib N, Monteagudo A, Ramos J, Berg R, Kovács S. Cesarean scar pregnancies: experience of 60 cases. J Ultrasound Med. 2015;34(04):601-610. Doi: 10.7863/ultra.34.4.601

18 Cali G, Forlani F, Timor-Tritsch IE, Palacios-Jaraquemada J, Minneci G, D'Antonio F. Natural history of Cesarean scar pregnancy on prenatal ultrasound: the crossover sign. Ultrasound Obstet Gynecol. 2017;50(01):100-104. Doi: 10.1002/uog.16216

19 Kaelin Agten A, Cali G, Monteagudo A, Oviedo J, Ramos J, TimorTritsch I. The clinical outcome of cesarean scar pregnancies implanted "on the scar" versus "in the niche". Am J Obstet Gynecol. 2017;216(05):510.e1-510.e6. Doi: 10.1016/j.ajog.2017.01.019

20 Kim SY, Yoon SR, Kim MJ, Chung JH, Kim MY, Lee SW. Cesarean scar pregnancy; Diagnosis and management between 2003 and 2015 in a single center. Taiwan J Obstet Gynecol. 2018;57(05): 688-691. Doi: 10.1016/j.tjog.2018.08.013

21 Vo TM, Van T, Nguyen L, Tran Q. Management of cesarean scar pregnancy among Vietnamese women. Gynecol Minim Invasive Ther. 2019;8(01):12-18. Doi: 10.4103/GMIT.GMIT_8_18
22 Timor-Tritsch IE, Monteagudo A, Bennett TA, Foley C, Ramos J, Kaelin Agten A. A new minimally invasive treatment for cesarean scar pregnancy and cervical pregnancy. Am J Obstet Gynecol. 2016;215(03):351.e1-351.e8. Doi: 10.1016/j.ajog.2016.03.010

23 Ravhon A, Ben-Chetrit A, Rabinowitz R, Neuman M, Beller U. Successful methotrexate treatment of a viable pregnancy within a thin uterine scar. Br J Obstet Gynaecol. 1997;104(05):628-629. Doi: 10.1111/j.1471-0528.1997.tb11547.x

24 Wang S, Beejadhursing R, Ma X, Li Y. Management of Caesarean scar pregnancy with or without methotrexate before curettage: human chorionic gonadotropin trends and patient outcomes. BMC Pregnancy Childbirth. 2018;18(01):289. Doi: 10.1186/ s12884-018-1923-x

25 Lai YM, Lee JD, Lee CL, Chen TC, Soong YK. An ectopic pregnancy embedded in the myometrium of a previous cesarean section scar. Acta Obstet Gynecol Scand. 1995;74(07):573-576. Doi: 10.3109/ 00016349509024394

26 Xiao Z, Cheng D, Chen J, Yang J, Xu W, Xie Q. The effects of methotrexate and uterine arterial embolization in patients with cesarean scar pregnancy: A retrospective case-control study. Medicine (Baltimore). 2019;98(11):e14913. Doi: 10.1097/MD.0000000000014913

27 Lee CL, Wang CJ, Chao A, Yen CF, Soong YK. Laparoscopic management of an ectopic pregnancy in a previous Caesarean section scar. Hum Reprod. 1999;14(05):1234-1236. Doi: 10.1093/humrep/14.5.1234

28 He Y, Wu X, Zhu Q, Wu X, Feng L, Wu X, et al. Combined laparoscopy and hysteroscopy vs. uterine curettage in the uterine artery embolization-based management of cesarean scar pregnancy: a retrospective cohort study. BMC Womens Health. 2014; 14:116. Doi: 10.1186/1472-6874-14-116

29 Wang DB, Chen YH, Zhang ZF, Chen P, Liu K-R, Li Y, et al. Evaluation of the transvaginal resection of low-segment cesarean scar ectopic pregnancies. Fertil Steril. 2014;101(02):602-606. Doi: 10.1016/j.fertnstert.2013.10.024 